\title{
Effect of sarpogrelate treatment on the prognosis after endovascular therapy for critical limb ischemia
}

\author{
Mitsuyoshi Takahara $\cdot$ Hideaki Kaneto $\cdot$ \\ Naoto Katakami - Osamu Iida - Taka-aki Matsuoka • \\ Iichiro Shimomura
}

Received: 17 October 2012/ Accepted: 22 February 2013/Published online: 14 March 2013

(C) The Author(s) 2013. This article is published with open access at Springerlink.com

\begin{abstract}
Hydroxytryptamine type 2 antagonists are used to treat symptomatic peripheral arterial disease. However, it remains unknown as to whether the administration of sarpogrelate, a 5-hydroxytryptamine type 2 antagonist, improves the prognosis after endovascular therapy for critical limb ischemia (CLI). We performed a retrospective analysis using a database of 386 Japanese patients undergoing endovascular therapy for CLI. Sixty-seven patients were treated with sarpogrelate, and we compared their prognosis with that of an equal number of backgroundmatched controls extracted from the population. The primary end point was the first event of either major amputation or death from any cause, and amputation-free survival was evaluated. The follow-up period was $21 \pm 18$ months (mean \pm standard deviation), and 58 end points were observed. Patients treated with sarpogrelate had a significantly higher amputation-free survival rate than their matched controls $(P=0.036)$. The hazard ratio for the end point and its $95 \%$ confidence interval was $0.57(0.34-0.97)$. These results suggest that sarpogrelate treatment is associated with a favorable prognostic outcome in CLI patients undergoing endovascular therapy. Future prospective studies are required to investigate whether sarpogrelate treatment would improve the prognosis of CLI patients.
\end{abstract}

M. Takahara · H. Kaneto $(\bowtie) \cdot$ N. Katakami · T. Matsuoka ·

I. Shimomura

Department of Metabolic Medicine,

Osaka University Graduate School of Medicine,

2-2 Yamadaoka, Suita,

Osaka 565-0871, Japan

e-mail: kaneto@endmet.med.osaka-u.ac.jp

O. Iida

Department of Internal Medicine,

Kansai Rosai Hospital, Hyogo, Japan
Keywords Sarpogrelate $\cdot 5$-hydroxytryptamine type 2 antagonist · Critical limb ischemia - Amputation-free survival

\section{Introduction}

Critical limb ischemia (CLI) is the most advanced stage of peripheral arterial disease (PAD) characterized by chronic ischemic rest pain or tissue loss [1], and is associated with a poor prognosis for both life and limb and has a major impact on the quality of life [2]. Even after revascularization, a substantial number of patients are still likely to suffer a poor prognosis [3]. Therefore, it is of great interest as to whether there is any medication that can modify their prognosis after the revascularization procedures.

For the management of symptomatic PAD, clinical guidelines recommend naftidrofuryl, a 5-hydroxytryptamine type $2\left(5-\mathrm{HT}_{2}\right)$ antagonist, as well as cilostazol, a phosphodiesterase III inhibitor [1]. Previous clinical trials revealed that both medications improve claudication in PAD patients $[4,5]$. Recently, some studies have reported the promising effects of cilostazol on the prognosis of CLI patients [6], whereas the effects of 5- $\mathrm{HT}_{2}$ antagonists still remain to be investigated. Although naftidrofuryl is not clinically approved in Japan, another 5- $\mathrm{HT}_{2}$ antagonist, sarpogrelate, is available in clinical practice.

The aim of the current study was to investigate whether the administration of sarpogrelate improves the prognosis of Japanese patients undergoing endovascular therapy for CLI.

\section{Patients and methods}

We used a database of 411 consecutive CLI patients undergoing endovascular therapy in Kansai Rosai Hospital, Hyogo, 
Japan, between April 2003 and April 2010, which did not include patients with thromboangiitis obliterans. The database comprised patients' clinical characteristics at baseline and prospectively collected prognosis. Twenty-five patients $(6 \%)$ were excluded because of missing data. We included the remaining 386 patients (94\%), to retrospectively analyze the association between the administration of sarpogrelate and prognosis. The primary end point was the first event of either major amputation or death from any cause, and amputationfree survival was evaluated. Of the 386 patients, 67 (17\%) were treated with sarpogrelate. Since the clinical backgrounds were expected to be different between patients treated with and without sarpogrelate, we compared the prognosis of the 67 patients treated with sarpogrelate with that of an equal number of background-matched controls, extracted from the population, without sarpogrelate treatment. The investigation was approved by the ethics committee of Kansai Rosai Hospital, and informed consent was obtained from all patients.

Data are given as means and standard deviations for continuous variables or as percentages for dichotomous variables. Differences of continuous variables between two groups were evaluated by Student's $t$ test, whereas dichotomous variables between two groups were compared by the Fisher exact test, if not otherwise mentioned.
Amputation-free survival rate was plotted using the Kaplan-Meier method, and the difference between groups was assessed by the log rank test. The Cox proportional hazards regression model was used to calculate the hazard ratio of sarpogrelate for the end point and its $95 \%$ confidence interval. The model was also used to assess the interaction effect. A $P$ value of less than 0.05 was considered statistically significant. All statistical analyses were performed using SPSS Statistics Version 19 (SPSS, Chicago, IL, USA), except for pair matching, which was performed using R version 2.13.0 (The R Foundation for Statistical Computing).

\section{Results}

Of a total of 386 CLI patients, 67 (17\%) were treated with sarpogrelate at baseline and the remaining $319(83 \%)$ were not. Their clinical characteristics are shown in Table 1 . The patients treated with sarpogrelate had a lower prevalence of diabetes mellitus $(P=0.034)$ and were less likely to be treated with cilostazol $(P=0.004)$. None of the patients were treated with prasugrel or had drug-eluting stents fitted for revascularization. When the matched controls were
Table 1 Clinical characteristics of CLI patients treated with or without sarpogrelate
Data are mean \pm standard deviation or $n(\%)$

$* P<0.05$ compared with patients treated with sarpogrelate

\begin{tabular}{|c|c|c|c|}
\hline & \multirow{2}{*}{$\begin{array}{l}\text { Patients with } \\
\text { sarpogrelate }(n=67)\end{array}$} & \multicolumn{2}{|c|}{ Patients without sarpogrelate } \\
\hline & & $\begin{array}{l}\text { Overall } \\
(n=319)\end{array}$ & $\begin{array}{l}\text { Matched controls } \\
(n=67)\end{array}$ \\
\hline Male & $40(60 \%)$ & $217(68 \%)$ & $45(67 \%)$ \\
\hline Age (years) & $71 \pm 14$ & $71 \pm 10$ & $71 \pm 11$ \\
\hline Body mass index $\left(\mathrm{kg} / \mathrm{m}^{2}\right)$ & $21.0 \pm 3.2$ & $21.4 \pm 3.2$ & $21.0 \pm 2.7$ \\
\hline Nonambulatory state & $21(31 \%)$ & $134(42 \%)$ & $24(36 \%)$ \\
\hline Fontaine stage IV & $57(85 \%)$ & $258(81 \%)$ & $59(88 \%)$ \\
\hline Infection & $15(22 \%)$ & $68(21 \%)$ & $16(24 \%)$ \\
\hline \multicolumn{4}{|l|}{ Revascularization procedures } \\
\hline Stent use & $28(42 \%)$ & $159(50 \%)$ & $30(45 \%)$ \\
\hline Self-expanding stent & $27(96 \%)$ & $136(86 \%)$ & $29(97 \%)$ \\
\hline Infrapopliteal revascularization & $45(67 \%)$ & $228(71 \%)$ & $46(69 \%)$ \\
\hline \multicolumn{4}{|l|}{ Comorbidities } \\
\hline Coronary artery disease & $21(31 \%)$ & $115(36 \%)$ & $29(43 \%)$ \\
\hline Cerebrovascular disease & $20(30 \%)$ & $105(33 \%)$ & $17(25 \%)$ \\
\hline Diabetes mellitus & $41(61 \%)$ & $239(75 \%)^{*}$ & $47(70 \%)$ \\
\hline Hypertension & $60(90 \%)$ & $272(85 \%)$ & $60(90 \%)$ \\
\hline Dyslipidemia & $49(73 \%)$ & $246(77 \%)$ & $53(79 \%)$ \\
\hline Smoking & $39(58 \%)$ & $188(59 \%)$ & $42(63 \%)$ \\
\hline Hemodialysis & $29(43 \%)$ & $147(46 \%)$ & $27(40 \%)$ \\
\hline \multicolumn{4}{|l|}{ Antiplatelet therapy } \\
\hline Aspirin & $55(82 \%)$ & $282(88 \%)$ & $56(84 \%)$ \\
\hline Thienopyridines & $17(25 \%)$ & $113(35 \%)$ & $18(27 \%)$ \\
\hline Cilostazol & $29(43 \%)$ & $200(63 \%)^{*}$ & $33(49 \%)$ \\
\hline More than one agent & $36(54 \%)$ & $220(69 \%)^{*}$ & $40(60 \%)$ \\
\hline
\end{tabular}


extracted and then compared with the 67 patients treated with sarpogrelate, no significant differences in clinical characteristics were observed between the two groups (Table 1). The follow-up period was $21 \pm 18$ months, and 58 end points were observed. The period wherein revascularization was performed was not significantly different between the patients treated with and without sarpogrelate, either before or after matching $(P=0.175$ and 0.378 , by Mann-Whitney $U$ test).

Figure 1 shows the amputation-free survival rate of patients treated with sarpogrelate and their matched controls. The patients treated with sarpogrelate had a significantly higher rate of amputation-free survival than the matched controls ( $P=0.036$ by log rank test). The hazard ratio for the end point and its $95 \%$ confidence interval was 0.57 (0.34-0.97). No interaction effect was observed between sarpogrelate treatment and diabetes mellitus $(P=0.836)$.

\section{Discussion}

The current retrospective study suggests that the administration of sarpogrelate is associated with a higher amputation-free survival rate in Japanese patients undergoing endovascular therapy for CLI.

Management of cardiovascular ischemic diseases is a challenging issue in clinical practice [7-15]. Management of CLI is no exception; patients with CLI still have a poor prognosis even after revascularization. It is of clinical interest as to whether there is any treatment that can improve their prognosis [16-18]. Sarpogrelate is a 5-HT2 antagonist and is now clinically approved for symptomatic PAD in Japan. Although its mechanisms of action are not

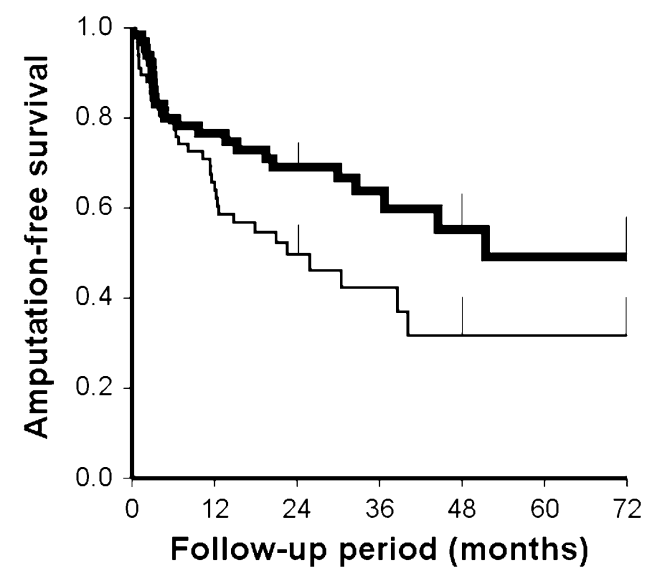

Fig. 1 Amputation-free survival in CLI patients treated with and without sarpogrelate. Amputation-free survival rates were estimated by the Kaplan-Meier method. Patients treated with sarpogrelate (thick line) had a higher amputation-free survival rate than the matched controls (thin line) $(P=0.036$ by log rank test). Error bars represent standard errors yet fully understood, previous reports showed that sarpogrelate reduces platelet aggregation [19, 20], improves endothelial function [21, 22], and enhances peripheral circulation [23, 24]. In addition, some clinical trials have demonstrated its favorable effects on cardiovascular diseases [25] and skin ulcers [26], as well as intermittent claudication [27]. On the other hand, the potential effects of sarpogrelate on the prognosis of CLI remain unrevealed. In the current study we performed a retrospective analysis to investigate the association of sarpogrelate treatment with the prognosis of CLI after endovascular procedures.

In the current study population, sarpogrelate was administered to $17 \%$ of the CLI patients undergoing endovascular therapy. The patients with sarpogrelate treatment were less likely to be treated with cilostazol $(P=0.004)$, which would be clinically explainable. Both sarpogrelate and cilostazol are expected to relieve PADrelated symptoms, and clinicians would reasonably assume the two medications as equals in the management of symptomatic PAD [27]. Therefore, it would be no surprise if patients already treated with one of the medications are not treated with the other.

Another difference in clinical characteristics between patients treated with and without sarpogrelate was the prevalence of diabetes mellitus. Patients treated with sarpogrelate had a lower prevalence of diabetes mellitus $(P=0.034)$; in other words, diabetic patients were less likely to be treated with sarpogrelate. Diabetic patients often suffer decreased pain sensation [28, 29], so CLI patients with diabetes mellitus might not feel foot pain as severely as those without diabetes. Sarpogrelate is expected to relieve the symptoms related to PAD. It would be no surprise that the administration of sarpogrelate was associated with the severity of symptoms. In the diabetic CLI patients, less frequent complaints of pain might lead to less frequent administration of sarpogrelate, although no data were available about the severity of neuropathy and symptoms in the current study population.

To minimize the prognostic influence of these different clinical backgrounds, we used matched controls to perform the comparison. As a result, the treatment with sarpogrelate was significantly associated with a favorable prognostic outcome $(P=0.036)$. However, the current analysis was retrospectively performed, which is its major limitation. The decision on the administration of sarpogrelate was left to the judgment of each doctor. We could not obtain data about the reason why each patient was treated with sarpogrelate. Covariates that were not taken into consideration in the current study might affect the prognostic findings. Whether the administration of sarpogrelate can improve prognostic outcome, therefore, still remains unrevealed. Nonetheless, the current findings raise our clinical hope for prognostic improvement by way of sarpogrelate treatment in CLI 
patients after endovascular therapy. Future prospective controlled trials are required to confirm the efficacy of sarpogrelate treatment for a favorable prognostic outcome.

In conclusion, sarpogrelate treatment was associated with a favorable prognostic outcome in Japanese CLI patients undergoing endovascular therapy. Future prospective studies are required to investigate whether sarpogrelate treatment would improve the prognosis of CLI patients.

Acknowledgments Mitsuyoshi Takahara is a Research Fellow of the Japan Society for the Promotion of Science and previously received grant support from the Japan Foundation of Applied Enzymology.

Open Access This article is distributed under the terms of the Creative Commons Attribution License which permits any use, distribution, and reproduction in any medium, provided the original author(s) and the source are credited.

\section{References}

1. Norgren L, Hiatt WR, Dormandy JA, Nehler MR, Harris KA, Fowkes FG, Bell K, Caporusso J, Durand-Zaleski I, Komori K, Lammer J, Liapis C, Novo S, Razavi M, Robbs J, Schaper N, Shigematsu H, Sapoval M, White C, White J, Clement D, Creager M, Jaff M, Mohler E 3rd, Rutherford RB, Sheehan P, Sillesen H, Rosenfield K (2007) Inter-society consensus for the management of peripheral arterial disease (TASC II). Eur J Vasc Endovasc Surg 33(Suppl 1):S1-S75

2. Sprengers RW, Teraa M, Moll FL, de Wit GA, van der Graaf Y, Verhaar MC (2010) Quality of life in patients with no-option critical limb ischemia underlines the need for new effective treatment. J Vasc Surg 52:843-49.e1

3. Takahara M, Kaneto H, Iida O, Katakami N, Sakamoto F, Matsuoka TA, Ikeda M, Shimomura I (2011) No association of diabetic duration or insulin use with the prognosis of critical limb ischemia after endovascular therapy. J Atheroscler Thromb 18:1102-1109

4. Regensteiner JG, Ware JE Jr, McCarthy WJ, Zhang P, Forbes WP, Heckman J, Hiatt WR (2002) Effect of cilostazol on treadmill walking, community-based walking ability, and healthrelated quality of life in patients with intermittent claudication due to peripheral arterial disease: meta-analysis of six randomized controlled trials. J Am Geriatr Soc 50:1939-1946

5. Lehert P, Comte S, Gamand S, Brown TM (1994) Naftidrofuryl in intermittent claudication: a retrospective analysis. J Cardiovasc Pharmacol 23(Suppl 3):S48-S52

6. Soga Y, Iida O, Hirano K, Suzuki K, Kawasaki D, Miyashita Y, Tsuchiya T, Nobuyoshi M (2011) Impact of cilostazol after endovascular treatment for infrainguinal disease in patients with critical limb ischemia. J Vasc Surg 54:1659-1667

7. Arima M, Matsuda A, Nitta M, Yoshida K, Shimizu M (2012) A case of subacute thrombosis associated with clopidogrel resistance after implantation of a zotarolimus-eluting stent. Heart Vessels 27:106-109

8. Otsuka Y, Nakamura M, Kokubu N, Tonooka A, Inoue K, Higami T (2012) Diffuse in-stent restenosis of CYPHER(R) stent due to hypersensitivity reaction confirmed by pathohistological findings. Heart Vessels 27:110-113

9. Buja P, Lanzellotti D, Isabella G, Napodano M, Panfili M, Favaretto E, Iliceto S, Tarantini G (2012) Comparison between sirolimus- and paclitaxel-eluting stents for the treatment of older patients affected by coronary artery disease: results from a singlecenter allcomers registry. Heart Vessels 27:553-558

10. Valdes Chavarri M, Bethencourt A, Pinar E, Gomez A, Portales JF, Pomar F, Calvo I, Lopez-Minguez J, Valdesuso R, Moreu J, Martinez A, Nammas W (2012) Titanium-nitride-oxIde-coated stents multicenter registry in diaBEtic patienTs: the TIBET registry. Heart Vessels 27:151-158

11. Klomp M, Damman P, Beijk MA, Silber S, Grisold M, Ribeiro EE, Suryapranata H, Wojcik J, Sim KH, Tijssen JG, de Winter RJ (2012) Applying the National Institute for Clinical Excellence criteria to patients treated with the Genous Bio-engineered $\mathrm{R}$ stent: a sub-study of the e-HEALING (Healthy Endothelial Accelerated Lining Inhibits Neointimal Growth) worldwide registry. Heart Vessels 27:360-369

12. Ogita M, Sakakura K, Nakamura T, Funayama H, Wada H, Naito R, Sugawara Y, Kubo N, Ako J, Momomura S (2012) Association between deteriorated renal function and long-term clinical outcomes after percutaneous coronary intervention. Heart Vessels 27:460-467

13. Nicolini F, Molardi A, Verdichizzo D, Gallazzi MC, Spaggiari I, Cocconcelli F, Budillon AM, Borrello B, Rivara D, Beghi C, Gherli $T$ (2012) Coronary artery surgery in octogenarians: evolving strategies for the improvement in early and late results. Heart Vessels 27:559-567

14. Vassalle C, Bianchi S, Battaglia D, Landi P, Bianchi F, Carpeggiani C (2012) Elevated levels of oxidative stress as a prognostic predictor of major adverse cardiovascular events in patients with coronary artery disease. J Atheroscler Thromb 19:712-717

15. Yuasa-Kawase M, Masuda D, Yamashita T, Kawase R, Nakaoka $\mathrm{H}$, Inagaki M, Nakatani K, Tsubakio-Yamamoto K, Ohama T, Matsuyama A, Nishida M, Ishigami M, Kawamoto T, Komuro I, Yamashita S (2012) Patients with CD36 deficiency are associated with enhanced atherosclerotic cardiovascular diseases. J Atheroscler Thromb 19:263-275

16. Ohno T, Kaneda H, Nagai Y, Fukushima M (2012) Regenerative medicine in critical limb ischemia. J Atheroscler Thromb 19:883-889

17. Oda M, Toba K, Kato K, Ozawa T, Yanagawa T, Ikarashi N, Takayama T, Suzuki T, Hanawa H, Masuko M, Kobayashi H, Aizawa Y (2012) Hypocellularity and insufficient expression of angiogenic factors in implanted autologous bone marrow in patients with chronic critical limb ischemia. Heart Vessels 27:38-45

18. Kim HG, Choi OH (2011) Neovascularization in a mouse model via stem cells derived from human fetal amniotic membranes. Heart Vessels 26:196-205

19. Uchiyama S, Ozaki Y, Satoh K, Kondo K, Nishimaru K (2007) Effect of sarpogrelate, a 5-HT(2A) antagonist, on platelet aggregation in patients with ischemic stroke: clinical-pharmacological dose-response study. Cerebrovasc Dis 24:264-270

20. Kajiwara I, Soejima H, Miyamoto S, Ogawa H (2011) Effects of additional treatment of sarpogrelate to aspirin therapy on platelet aggregation and plasma plasminogen activator inhibitor activity in patients with stable effort angina. Thromb Res 128:547-551

21. Jeong IS, Park JH, Jin SA, Kim JH, Lee JH, Choi SW, Jeong JO, Seong IW (2012) Oral sarpogrelate can improve endothelial dysfunction as effectively as oral cilostazol, with fewer headaches, in active young male smokers. Heart Vessels. doi: 10.1007/s00380-012-0282-1

22. Miyazaki M, Higashi Y, Goto C, Chayama K, Yoshizumi M, Sanada H, Orihashi K, Sueda T (2007) Sarpogrelate hydrochloride, a selective 5-HT2A antagonist, improves vascular function in patients with peripheral arterial disease. J Cardiovasc Pharmacol 49:221-227 
23. Tanaka T, Fujita M, Nakae I, Tamaki S, Hasegawa K, Kihara Y, Nohara R, Sasayama S (1998) Improvement of exercise capacity by sarpogrelate as a result of augmented collateral circulation in patients with effort angina. J Am Coll Cardiol 32:1982-1986

24. Horiuchi M, Okita K, Takada S, Omokawa M, Suga T, Morita N, Hirabayashi K, Yokota T, Kinugawa S, Tsutsui H (2010) Effects of oral single-dose administration of sarpogrelate hydrochloride on saturation $\mathrm{O}(2)$ of calf muscle during plantar flexion exercise. Adv Exp Med Biol 662:531-536

25. Fujita M, Mizuno K, Ho M, Tsukahara R, Miyamoto A, Miki O, Ishii K, Miwa K (2003) Sarpogrelate treatment reduces restenosis after coronary stenting. Am Heart J 145:E16
26. Yoshimasu T, Ikeda T, Uede K, Kanazawa N, Furukawa F (2012) Effects of sarpogrelate hydrochloride on skin ulcers and quality of life in patients with systemic sclerosis. J Dermatol 39:536-540

27. The Japanese Circulation Society (2009) Guidelines for management of peripheral arterial occlusive diseases. Circ J 73(Suppl. III): $1507-1569$

28. American Diabetes Association (2003) Peripheral arterial disease in people with diabetes. Diabetes Care 26:3333-3341

29. Jude EB, Eleftheriadou I, Tentolouris N (2010) Peripheral arterial disease in diabetes-a review. Diabet Med 27:4-14 